\title{
A pilot study on high dosage intervention of children with CP using combined therapy approaches
}

\author{
Dorothy Charmaine Russell, B OT (UFS), M OT (UFS), PhD OT (UFS) \\ Senior Occupational Therapist / Director at Bloemfontein Child Information Centre, Faculty of Health Sciences, Department of \\ Paediatrics and Child Health, University of the Free Sate
}

Christa Scholtz, B OT (UFS), M OT (UFS)

Private Practice Occupational Therapist, Therapy Centre, Klerksdorp

Petro Greyling, BSc PT (UFS)

Private Practice Physiotherapist. The Therapy Centre, Bloemfontein

Marin Taljaard, B OT (UFS)

Deputy Director: Occupational Therapy, Universitas Hospital, Bloemfontein

\section{Elmien Viljoen, B OT (UFS)}

Assistant Director: Occupational Therapy, Phuthuloha District Hospital, Ficksburg

\section{Corné Very, B OT (UFS), MBA (UFS)}

Assistant Director: Occupational Therapy, VERC, Bloemfontein

Background: Neurodevelopmental Therapy (NDT) in conjunction with other therapy approaches offer a forward-looking interdisciplinary problem-solving approach to the treatment and management of any individual with a central nervous system disorder.

Aim: The aim of the pilot study was to establish the effect of Combined Therapy Approaches (CTA) on the intervention of four children aged 48.I months to 60 months with Cerebral Palsy (CP). Repetitive learning processes of CTA during task specificity activities provide an overview of the impact of high dosage intervention for children with $C P$.

Methodology: A One-Group Pre-test-Post-test Design was followed. The pilot study included four children with active participation of the parents during frequent intervention sessions. The children were classified on the Gross Motor Function Classification System (GMFCS) at levels IV and V with some homogeneity. All children were evaluated before intervention, directly after intervention sessions and again at eight weeks after the initial testing using the Paediatric Evaluation of Disability Inventory Computer Adaptive Test (PEDICAT) and Gross Motor Function Measure (GMFM). Goal Attainment Scaling (GAS) that involves careful prediction of expected outcomes enabled a thorough description of the children's level of performance in a target area.

Results: The success of the intervention was confirmed by the positive results obtained on the Goal Attainment Scaling (GAS).

Conclusion: Intensive task-specific training showed to be beneficial for the children, resulting in improved developmental domains for the child with CP. These findings emphasize that evidence-based treatment-intervention approaches for children with $C P$ should be applied including traditional NDT/Bobath.

Key words: Cerebral Palsy, Cerebral Palsy intervention, Goal Attainment Scaling (GAS) goals, High dosage intervention, Neurodevelopmental Therapy

\section{INTRODUCTION}

Despite the widespread use of Neurodevelopmental Therapy (NDT) in paediatric practice, the short- or long-term benefits of this approach have not been systematically investigated. NDT is an approach used for children of all ages with Cerebral Palsy (CP) who present with sensory-motor-perceptual and communication dysfunction'. Authors of meta-analytic reviews ${ }^{2}$ report positive trends, but conclusive evidence on the efficacy of NDT for the improvement of activity and participation is still to be established. Standardised guidelines as well as a fidelity measure for NDT intervention will aid in determining the effectiveness of this approach, which is still questionable according to $\mathrm{Paci}^{3}$. A review by Novak, et $\mathrm{al}^{4}$ also highlighted the lack of a sufficient evidence-base for the continuing adaptations of the NDT/Bobath approach that have been applied by therapists across cultures and continents for the past
70 years ${ }^{5}$. Therefore, an eclectic approach which includes theories of motor control, task-oriented approaches and evidence-based interventions, was used in the intervention of children with CP. The aim of this pilot study was to provide an overview of an intervention protocol for children with CP using high-dosage Combined Therapy Approaches (CTA). It is hypothesised that the protocol will lead to functional improvements in children with $\mathrm{CP}$.

\section{LITERATURE REVIEW}

The Bobath/NDT concept was initially based on the hierarchical model theory, but has since shifted to the current systems theory. This change enables the emphasis to be placed on a balanced distribution of the control of behaviour among interactive neural and body systems that are spontaneously organised by the task parameters in the context in which the task intentionally occurs ${ }^{6}$. 
The NDT approach offers an interdisciplinary, problem-solving approach to the assessment, treatment and management of any individual with limited abilities, to fully participate in daily life. Central nervous system (CNS) disorders can impair motor (including tone and patterns of movement), sensory, perceptual, communication and cognitive function ${ }^{4}$. The NDT/Bobath concept relies on the observational, analytical and handling skills of the therapist which in most cases cannot be quantified. Since the chosen interventions are uniquely designed and implemented for each individual, it is not an operationally definable concept.

Every effort is made to activate and stimulate spared neural mechanisms and to stimulate the child to use affected body parts and sensory-perceptual pathways. Stimulating the child in this way aims to drive neural plasticity and minimise learned developmental, non-use or neglect in all domains ${ }^{7}$. Quality remains important; it is however, never preferred to function, for when a child's movement can't be improved, function should not be compromised ${ }^{8}$. It is believed that the child's potential is identified by tasks that can be executed with only a little help'. It is important to focus on the potential of the child and further enhance it with specific intervention. To estimate what 'a little help' is, the therapist uses preparation, activation and repetition with task-specifics with or without facilitation from distal or proximal key points of control'.

The International Classification of Functioning, Disability and Health (ICF-CY) provides a comprehensive view of functioning and constitutes a universal language for interdisciplinary work with children ${ }^{8}$. It offers a common framework with information on child functioning from medical, psychological, social, educational and environmental perspectives. The ICF-CY is useful as a means for describing the status of children with $\mathrm{CP}^{10}$. The NDT approach has a strong association with the ICF-CY in that it considers children as 'moving targets', changing in all domains over time and seeks to minimise health issues ${ }^{8}$.

Theories of motor control, task-oriented approaches and evidence-based interventions, are optimally incorporated and appropriate credit to sources is given in this pilot study.

A task-oriented approach based on the Dynamic Systems Theory (where motor development is considered as a process of self-organisation) is catalysed by the interaction between multiple factors such as body weight, muscle strength, joint configuration, the patient's mood, specific environmental conditions and brain development ${ }^{11}$. A systems model of motor control ${ }^{12}$ and theories of motor learning ${ }^{13}$, as well as mobilisation with trigger points are incorporated. Occupation based on the treatment principles of client-centred approaches are applied ${ }^{14}$. The client-centred approach is further strengthened by the following theories:

* Action perception is a function of the patient's ability to perceive their environment. Factors that influence this ability include body size, body control, energy potential and the demands of the tas $\mathrm{k}^{15}$. The environment may be adapted to enable the patients to hold and maintain grasp of a toy.

* The Neuronal Group Selection Theory (NGST)" offers the perfect balance to promote effective intervention in children with motor dysfunction. According to NGST the ensemble of cortical and subcortical systems is dynamically organised into variable networks, the structure and function of which are selected by development and behaviour. The units of selection are collections of hundreds to thousands of strongly interconnected neurons, called neuronal groups. These groups act as functional units dealing with a specific type of motor behaviour or information from a specific sensory modality. Development starts with primary neuronal repertoires, which then proceeds to selection on the basis of afferent information produced by behaviour and experience. Severely affected CP children experience little functionally relevant activities and have reduced repertoires in spontaneous posture and motility". Their experiences ca be changed by a variety of activities. * Sensory stimulation is included as daily events and situations are drenched with sensation ${ }^{16}$. Sensory stimulation consists of activities that promote visual perception, body awareness, tactile perception and visual-motor coordination ${ }^{16}$.

* The advantage of Induced Constraint Movement Therapy (CIMT) and bimanual training ${ }^{17,18}$ is that the restraint allows the interventionist to focus on and isolate the more affected limb. Findings show that neuro-rehabilitation through the use of CIMT can be effective ${ }^{19}$.

* The brain is capable of recovering after a neurological incident through the ability of neurons and other brain cells to alter their structure and function (plasticity) in response to a variety of external and internal pressures, including behavioural training ${ }^{20}$. Therefore $\mathrm{CP}$-specific early intervention maximises neuro-plastisity ${ }^{18}$.

Most interventions are presented in specific dosages (strengthening, gait training, or learning to use a power chair) and have as primary focus the changing of body structures and function, activity, or participation outcomes. There is no specified dosage allocated for a holistic approach for children with $\mathrm{CP}^{21}$. A randomised control trial specific for CIMT and bi-manual training synthesis suggests that more practice has proved to be favourable. Specifically, 90 hours over 15 days resulted in better improvement than 60 hours over ten days. A 30-minute session, either twice a day for two weeks or twice a week for at least six weeks, improved endurance and gait speed. Frequency and time spent in treatment appear to be critical to the success of either child- or context-based interventions. Thresholds for time to produce changes in performance (given the variation in age, level of severity, and intensity of work in a session) warrant further investigation. A study using NDT intervention in children with Down Syndrome indicated that children older than I8 months can tolerate interventions for 20-40 minute sessions once every second week for six months ${ }^{22}$.

\section{METHODS}

\section{Study design}

A One-Group Pre-test-Post-test Design ${ }^{23}$ was followed.

\section{Population and sampling}

A convenience sample of four children with a confirmed diagnosis of CP made by a paediatric neurologist was used ${ }^{24}$. Children aged 48. I to 60 months with a classification of IV or V on the Gross Motor Function Classification Systems (GMFCS ${ }^{25}$ and whose parents agreed to comply with the intervention protocol, were recruited for the study from two Centres in Bloemfontein, South Africa.

The sample consisted of one boy and three girls. Three participants were diagnosed with quadriplegic CP in GMFCS level $V$ and one was diagnosed with left hemiplegia in GMFCS level IV.

Exclusion criteria included botulinum toxin A (BoNT-A) intervention, surgery such as tendon lengthening or other orthopaedic procedures and central visual impairment (as this could influence postural control ${ }^{26}$ ).

The optimal dosage was determined by the interventionist who is an experienced occupational therapist in the field of CP. Previous studies suggested the following dosage: ten days of 60 hours or 90 hours over 15 days or 30-minute sessions either twice a day for two weeks or twice a week for six weeks ${ }^{21}$. The consented dosage for this pilot was five hours per day of intervention over five days at the Bloemfontein Child Information Centre, resulting in a total of 25 hours of intervention.

\section{Outcome tools}

The participants were evaluated on three occasions (a pre-test and two post-tests) using the Paediatric Evaluation of Disability Inventory Computer Adaptive Test (PEDI-CAT) and the Gross Motor Function Measure (GMFM). Goal Attainment Scaling (GAS) as a measuring tool for establishing treatment goals was completed for the four participants in the intervention group. There was no specific goal identified which was common among the participants. 
I. The PEDI-CAT ${ }^{27}$ measures abilities in four domains: Daily Activities, Mobility, Social/Cognitive function and Responsibility domain. In the PEDI-CAT measures the extent to which the caregiver or child takes responsibility for managing complex, multi-step life tasks.

2. The GMFM is a standardised observational instrument that has been designed for use in both clinical and research settings to measure changes in gross motor function over time in children with $\mathrm{CP}^{25}$. Due to time constraints, the GMFM-66 was used in this study ${ }^{28}$. The GMFM-66 is an updated version of the GMFM88 that evaluates 66 items to measure gross motor function in children with CP, namely: lying and rolling (4 items), sitting ( 15 items), crawling and kneeling ( 10 items), standing ( 3 items) as well as walking, running and jumping (24 items) ${ }^{25}$.

3. Goal Attainment Scaling (GAS) is a method for quantifying progress on personal goals using a semi-structured interview ${ }^{29}$. The GAS detects clinically significant change ${ }^{29}$ and is an effective way of achieving behavioural change in patients ${ }^{30}$. The following three descriptions encapsulate the GAS: (a) a set of goals are specified, (b) weights are assigned to each goal according to priority; (c) a continuum of possible outcomes that could be expected per goal are specified (worst expected outcome (-2)), less than expected outcome $(-I)$, expected outcome $(0)$, more than expected outcome $(+I)$, and best expected outcome $(+2)$ ). The GAS's four steps were followed. The first step consisted of identifying the patient's or parent's expectations and the environmental factors influencing the performance of the activity in question for example sustaining cylindrical grasp on a spoon during feeding (Table IV (I) page 30). The second step consisted of determining the observable target behaviour corresponding to the target activity (e.g. holding a toy). Identifying the assistance required to perform an activity, is the third step. Typical assistance requirements were: interventionist assistance, technical aids, assistive devices, verbal guidance and cognitive assistance. The fourth step consisted of quantifying the initial performance of the target activity in terms of the time required. The measurement of the target behaviour can be regarded as a frequency, since as an example, the number of seconds the child needs to hold on to an object is recorded. The five attainment levels were then determined by adding or changing the 'assistance required' and/or 'performance quantification' categories per individual. Only one characteristic at a time was allocated to a goal ${ }^{29}$ (Table I below).

Table I

\begin{tabular}{|c|c|c|c|c|}
\hline Intervention approaches & RJ & MvW & RC & RK \\
\hline \multicolumn{5}{|c|}{ Task oriented approach } \\
\hline Motor control & $x$ & $x$ & $x$ & $x$ \\
\hline Motor learning & $x$ & $x$ & $x$ & $x$ \\
\hline Mobilization with trigger points & $x$ & $x$ & $x$ & $x$ \\
\hline \multicolumn{5}{|c|}{ Client oriented approach } \\
\hline Action perception & & & $x$ & \\
\hline Neuronal group selection & $x$ & $x$ & $x$ & $x$ \\
\hline Sensory stimulation & $x$ & $x$ & $x$ & $x$ \\
\hline $\begin{array}{l}\text { Induced constraint and bi-manual } \\
\text { training }\end{array}$ & & & $x$ & \\
\hline Neuroplasticity & $x$ & $x$ & $x$ & $x$ \\
\hline NDT/Bobath & $x$ & $x$ & $x$ & $x$ \\
\hline
\end{tabular}

\section{Intervention sessions}

\section{Interventionist}

An experienced occupational therapist in the field of CP developed an intervention protocol based on Combined Therapy Approaches
(CTA) and is summarised in this section. The active and intensive therapy programme for this study was compiled by the interventionist, having a background as a senior Occupational Therapist tutor, certified in paediatric NDT and with clinical neurological experience. Therefore clinical reasoning and prior knowledge played a crucial role in preparing this intervention programme. The programme consisted of high task-specific ${ }^{18}$ repetitions within a specific context.

\section{Structured sessions}

Daily 60 - 90-minute hands-on facilitation with parent participation was done. There were five different activity participation training stations acting as a home-programme. These training stations included the following:

* Activities for upper and lower extremities

* Activities to stimulate upright posture in standing

* Mobilisation of upper extremity and neck

* Visual Activities for example localisation with eye shift

- Activities of Daily Living (ADL) such as feeding management, dressing in lying and sitting position, mobilisation (to activate muscles and time the sequence of muscles), playing in the standing, side-lying and sitting positions, sleeping and resting, carrying and transferring as well as the introduction of adaptive equipment at home.

\section{Principles}

Tasks were allocated to each participant by considering the following:

* The task specificity ${ }^{17}$ is an active challenging practice, the selected task should not be too easy nor too difficult. The intensity was manipulated by changing the degrees of freedom, speed of movement, loading the objects for strength and or using equipment for arm/leg weight support (by using suspension equipment against gravity), changes in the lever arm, range of motion, endurance (cardiovascular), cognitive and perceptual activities and the frequency of upper extremity use.

* Activities should be relevant and meaningful, therefore optimal adaptation to engage motor learning was vital for the activity selection.

* The repetition of movement results in improvement in that specific movement; large amounts of practice (different tasks) are required to fully master a motor skill. The principle of experience-dependent neural plasticity and their translation to the damaged brain were incorporated in the intervention ${ }^{31}$.

* Feedback on the outcomes play a pivotal role in creating an optimal learning environment. Therefore, learning requires problem solving not rote (habit/memorised) repetition.

* An activity should involve a complete task repetition. It is more effective than executing partial task repetitions ${ }^{31}$.

* Any ability of a specific movement, even small should be implemented in an activity. The "Use it or lose it" and "Use it and improve it" principles were incorporated ${ }^{31}$.

* Occupations should be incorporated on the level of creativity. Visual activities to emphasise accomplishments and awareness of environment were used.

* Time allocations to activity participation matters, therefore dosage is important. Dosage should be appropriate to ultimately facilitate relevant responses. The dosage for this study was five hours intervention per day for five consecutive days. The total hours of intervention for each child was 25 hours over the five days ${ }^{32}$.

\section{Interventions}

* Focused on changes in body structures and function:

During intervention the body functions, structures and environment were prepared as well as the adapted equipment necessary within an activity or immediately prior to it. The interventionist followed the child when working within the activity or skill using minimal handling to not interrupt or interfere with the child's ability to achieve a goal independently ${ }^{26}$. 


\begin{tabular}{|c|c|c|c|c|}
\hline \multicolumn{3}{|c|}{ PEDI-CAT Median scores } & \multirow{2}{*}{$\begin{array}{c}\text { INTERVENSION } \\
-5.675\end{array}$} & \multirow[t]{2}{*}{ p-value } \\
\hline \multirow{3}{*}{ Daily activities } & Pre-Test & $(n=4)$ & & \\
\hline & Post-Test & $(n=4)$ & -3.675 & 0.25 \\
\hline & Post 8 weeks & $(n=4)$ & -3.675 & 0.125 \\
\hline \multirow{3}{*}{ Mobility } & Pre-Test & $(n=4)$ & -8.035 & \\
\hline & Post-Test & $(n=4)$ & -6.04 & 0.125 \\
\hline & Post 8 weeks & $(n=4)$ & -7.49 & 0.375 \\
\hline \multirow{3}{*}{ Social/Cognitive } & Pre-Test & $(n=4)$ & -7.07 & \\
\hline & Post-Test & $(n=4)$ & -4.925 & 0.125 \\
\hline & Post 8 weeks & $(n=4)$ & -5.41 & 0.125 \\
\hline \multirow{3}{*}{ Responsibility } & Pre-Test & $(n=4)$ & -4.44 & \\
\hline & Post-Test & $(n=4)$ & -4.25 & 1 \\
\hline & Post 8 weeks & $(n=4)$ & -4.44 & I \\
\hline
\end{tabular}

* Focused on changes in activity:

The intervention consisted of the repetition of specific tasks suitable to be integrated in a game-like scenario', such as reaching for an object which was in a vertical position. Then these tasks were carried over into ADL, play, perception and communication with and without equipment after the handson session.

* Aimed at changing participation:

Parent and child participation were a priority. An element of motivation and active participation were present for each prepared task of the four participants and the parents. All tasks were selected according to the participants' GAS goals as summarised in Tables IV-VII on pages 30-3I, presented in the results section.

\section{Error of measurements}

It is difficult to evaluate the effectiveness of any motor therapy approach ${ }^{4,32}$, because the specific sequence of treatments that were delivered are not standardised. Previous studies evaluating the effectiveness of NDT/Bobath could also be affected by the skill level of the therapists, which is seldom specified ${ }^{32}$. The constructs of NDT/Bobath itself have changed over time, and NDT/Bobath strategies are commonly combined with other therapy techniques and medical treatments ${ }^{32}$. It remains a challenge to obtain unbiased results as there is no definite standardised motor therapy approach yet. The GAS goals for each participant could have been overcautiously done as reflected in the improved results. The same evaluators were used for the pre-and post-tests and were not involved in any intervention.

\section{Data analysis}

The data were summarised using descriptive statistics namely median and quartiles. The Wilcoxon signed-rank test is a nonparametric test and similar to the paired $t$-test when two variables are compared in a single sample ${ }^{33}$. The data analysis was performed by the Department of Biostatistics of a University, using the software package SAS. The analysis of GAS goals was done independently by a mathematical statistician.

\section{Ethical considerations}

Ethical approval from the Ethics Committee of the Faculty of Health Sciences of University of the Free State was obtained prior to implementing this research project (ECU no. 2/3/2014). Application was done at the NHREC (application ID 3896).

Since all the participants were less than 72 months old, written informed consent was obtained from all the parents. Parents were informed that participation in the study was voluntary and that they had the right to withdraw from the programme at any time without prejudice.

\section{RESULTS}

The Pedi-Cat's Daily Activities domain scores showed a slight improvement as reflected in the p-values $(0.25-0.125)$ (Table II)

The GMFM median scores (Table III page 30) showed slight improvement for both post-tests, but did not result in statistical significance ( $p$-value $=0.13$ ).

All participant's specific tasks with their goals for the intervention group were reflected in Tables IV-VII (pages 30-3I). This showed that the goals were attained after five days of task specific intervention.

The goal weightings and baselines scores of all the participants are presented in Table VIII (I-4) (page $3 I$ and 32). The sum for this participants were 24, 29, 27 and 29 using the formula of GAS ${ }^{34}$.

T-scores should be distributed around a value of 50 with a standard deviation of 10 . The T-baseline score for all participants had improved (22.6I \& 22.29 to $77.20 \& 77.38)^{29}$.

\section{DISCUSSION}

The main goal of this study was to determine an intervention protocol which entails actual activities for therapy that could be used in ADL.

The intervention during this pilot study was rooted in behavioural training theory ${ }^{20}$.

Task specificity training is recommended for $\mathrm{CP}$ as it induces neuroplasticity and functional gains ${ }^{18}$. The results suggest that task specificity training with intensity, effectively improve developmental outcomes with a positive impact on the motor and ADL developmental domains of the child with $\mathrm{CP}^{17,18}$. Even though not statistically significant, the results showed a positive trend after eight weeks in the gross-motor/mobility developmental domain, social/cognitive domain and activities of daily living (Tables II above and Table III (page 30). The results showed no evidence of immediate, or short- to medium-term benefits once a qualitative change had occurred and after sufficient frequency of treatment ${ }^{4}$. This pilot study showed sustained improvement for eight weeks. This could be considered as 'learning within a motor learning approach".

Even though NDT/Bobath offers a forward-looking interdisciplinary (central in the Bobath concept) problem-solving approach, the intervention approach for this pilot study included NDT/Bobath intervention as well as CTA. It was further explored within the scope of Occupational Therapy practice as the foundation. The Dynamic Systems Theory" was paramount to this intervention, especially with the inclusion of the inclusion of the visual system, which is also not part of NDT/Bobath approach.

This pilot study was based on the hypothesis that an intensive holistic intervention approach will lead to functional improvements, with task specificity training ${ }^{17,18}$. According to the Novak et al. ${ }^{15}$ review the following interventions were effective for the child with 
Table III: GMFM median scores

\begin{tabular}{|c|c|c|c|c|}
\hline GMFM Median Scores & & & INTERVENSION & p-value \\
\hline \multirow{3}{*}{$\begin{array}{l}\text { Dimension A } \\
\text { Lying \& Rolling }\end{array}$} & Pre-Test & $(n=4)$ & 2.00 & \\
\hline & Post-Test & $(n=4)$ & 3.00 & 0.5 \\
\hline & Post 8 weeks & $(n=4)$ & 3.00 & 0.5 \\
\hline \multirow{3}{*}{$\begin{array}{l}\text { Dimension B } \\
\text { Sitting }\end{array}$} & Pre-Test & $(n=4)$ & 3.00 & \\
\hline & Post-Test & $(n=4)$ & 4.00 & 0.25 \\
\hline & Post-8 weeks & $(n=4)$ & 6.50 & 0.13 \\
\hline \multirow{3}{*}{$\begin{array}{l}\text { Dimension C } \\
\text { Crawling \& Kneeling }\end{array}$} & Pre-Test & $(n=4)$ & 0.00 & \\
\hline & Post-Test & $(n=4)$ & 0.00 & \\
\hline & Post 8 weeks & $(n=4)$ & 0.00 & \\
\hline \multirow{3}{*}{$\begin{array}{l}\text { Dimension D } \\
\text { Standing }\end{array}$} & Pre-Test & $(n=4)$ & 0.00 & \\
\hline & Post-Test & $(n=4)$ & 0.00 & \\
\hline & Post 8 weeks & $(n=4)$ & 0.00 & \\
\hline \multirow{3}{*}{$\begin{array}{l}\text { Dimension E } \\
\text { Walking \& jumping }\end{array}$} & Pre-Test & $(n=4)$ & 0.00 & \\
\hline & Post-Test & $(n=4)$ & 0.00 & \\
\hline & Post 8 weeks & $(n=4)$ & 0.00 & \\
\hline \multirow[t]{3}{*}{ Total } & Pre-Test & $(n=4)$ & 1.78 & \\
\hline & Post-Test & $(n=4)$ & 2.34 & 0.25 \\
\hline & Post 8 weeks & $(n=4)$ & 3.15 & 0.13 \\
\hline
\end{tabular}

Table IV: GAS scales written for a CP child with Multi-disabilities that complicate functioning (I)

\begin{tabular}{|l|l|l|l|}
\hline \multicolumn{5}{|c}{ GAS scales written for a CP child with multi disabilities that complicates functioning (RJ) } \\
\hline $\begin{array}{l}\text { Goal attainment } \\
\text { scale }\end{array}$ & $\begin{array}{l}\text { The child's main goal: Sustained cylindrical } \\
\text { grasp on spoon during feeding }\end{array}$ & $\begin{array}{l}\text { The child's main goal: Spontaneous } \\
\text { kicking for self regulation }\end{array}$ & $\begin{array}{l}\text { The child's main goal: Mouth closure } \\
\text { on spoon during feeding }\end{array}$ \\
\hline & Observable target behaviour: holding a toy & $\begin{array}{l}\text { Observable target behaviour: } \\
\text { alternate kicking }\end{array}$ & $\begin{array}{l}\text { Observable target behaviour: taking } \\
\text { food from a spoon }\end{array}$ \\
\hline-2 & Drop cylinder immediately after grasp & No awareness & Bite reflex or tong thrust \\
\hline-1 & Hold object for $\mathbf{5 ~ s e c}$ & No attempt to kick & No active lateral chewing \\
\hline 0 & Hold object for $\mathbf{1 0 ~ s e c}$ & Attempt to kick & Activate lateral chewing for swallowing \\
\hline+1 & Hold object for $\mathbf{1 5}$ sec & Alternate kicking 4 times & Lateralization of tong \\
\hline+2 & Hold object and attempts to shake it & Alternate kicking I0 times & Able to actively take food from spoon \\
\hline
\end{tabular}

Table V: GAS scales written for a CP child with Multi-disabilities that complicate functioning (2)

\begin{tabular}{|c|c|c|c|}
\hline \multicolumn{4}{|c|}{ GAS scales written for a CP child with multi disabilities that complicates functioning (RC) } \\
\hline $\begin{array}{l}\text { Goal attainment } \\
\text { scale }\end{array}$ & $\begin{array}{l}\text { The child's main goal: Maintain object in } \\
\text { hand }\end{array}$ & $\begin{array}{l}\text { The child's main goal: Standing in } \\
\text { frame for conversations }\end{array}$ & $\begin{array}{l}\text { The child's main goal: Encourage arm } \\
\text { use by transfer over hemi arm }\end{array}$ \\
\hline & $\begin{array}{l}\text { Observable target behaviour: Register L } \\
\text { hand }\end{array}$ & $\begin{array}{l}\text { Observable target behaviour: } \\
\text { weightbearing on lets }\end{array}$ & $\begin{array}{l}\text { Observable target behaviour: } \\
\text { transitions }\end{array}$ \\
\hline-2 & $\begin{array}{l}\text { No visual and/or registration of effected } \\
\text { side (L) }\end{array}$ & No standing & No attempt \\
\hline-1 & $\begin{array}{l}\text { No registration of tactile input on } \mathrm{L} \\
\text { side }\end{array}$ & $\begin{array}{l}\text { Stand with crying due to } L \text { knee } \\
\text { and ankle that couldn't support }\end{array}$ & Lifting head from floor \\
\hline 0 & Look at her hand when object is placed & $\begin{array}{l}\text { Placed in standing box chest height } \\
\text { for } 30 \text { minutes }\end{array}$ & $\begin{array}{l}\text { Wedge } 60 \text { degrees reach toy with } \\
\text { normal hand crossing midline where } \\
\text { toy was placed on left knee }\end{array}$ \\
\hline+1 & Take object out of $L$ hand & Stand with support for 60 minutes & Toys placed on non-affected side \\
\hline+2 & Maintain object in hand and move object & Sandwich standing & Transition from flat surface \\
\hline
\end{tabular}


Table VI: GAS scales written for a CP child with Multi-disabilities that complicate functioning (3)

\begin{tabular}{|l|l|l|l|}
\hline \multicolumn{4}{|l}{ GAS scales written for a CP child with multi disabilities that complicates functioning (MvW) } \\
\hline $\begin{array}{l}\text { Goal attainment } \\
\text { scale }\end{array}$ & $\begin{array}{l}\text { The child's main goal: Hold cylinder object } \\
\text { with movement }\end{array}$ & $\begin{array}{l}\text { The child's main goal: Standing in } \\
\text { frame for conversations }\end{array}$ & $\begin{array}{l}\text { The child's main goal: Voicing to get } \\
\text { mom's attention }\end{array}$ \\
\hline & Observable target behaviour: Holding a toy & $\begin{array}{l}\text { Observable target behaviour: } \\
\text { weight support on lets }\end{array}$ & $\begin{array}{l}\text { Observable target behaviour: } \\
\text { communication }\end{array}$ \\
\hline-2 & Can't open hand & Can't stand in frame & No voicing \\
\hline$-I$ & $\begin{array}{l}\text { Playing on side lying position with } \\
\text { stimulated on dorsal side of hand for } \\
\text { opening for grasp }\end{array}$ & 5 minutes standing in frame & Can voice only for 2 sec \\
\hline 0 & $\begin{array}{l}\text { Lying on side intermittently to grasp } \\
\text { and hold }\end{array}$ & 10 minutes & 5 sec \\
\hline+1 & Side lying hands open to grasp & 20 minutes & 6 sec \\
\hline+2 & $\begin{array}{l}\text { Side lying open to grasp and hold a cylinder } \\
\text { object with movement }\end{array}$ & 30 minutes & $\begin{array}{l}8 \text { sec: } 2 \text { syllables (yes and no } \\
\text { response) }\end{array}$ \\
\hline
\end{tabular}

Table VII: GAS scales written for a CP child with Multi-disabilities that complicate functioning (4)

GAS scales written for a CP child with multi disabilities that complicates functioning (RK)

\begin{tabular}{|c|c|c|c|}
\hline $\begin{array}{l}\text { Goal attainment } \\
\text { scale }\end{array}$ & $\begin{array}{l}\text { The child's main goal: Grasp for } \\
\text { manipulation }\end{array}$ & $\begin{array}{l}\text { The child's main goal: Standing } \\
\text { with assistance for transfer from } \\
\text { wheelchair to bed }\end{array}$ & $\begin{array}{l}\text { The child's main goal: Focus for } \\
\text { alternative communication }\end{array}$ \\
\hline & $\begin{array}{l}\text { Observable target behaviour: } \\
\text { Weightbearing on hands }\end{array}$ & $\begin{array}{l}\text { Observable target behaviour: } \\
\text { weightearing }\end{array}$ & $\begin{array}{l}\text { Observable target behaviour: Focus } \\
\text { on objects }\end{array}$ \\
\hline-2 & $\begin{array}{l}\text { No attempt to use arms for play or } \\
\text { protection }\end{array}$ & No standing & No awareness of visual stimulus \\
\hline-1 & $\begin{array}{l}\text { Limited use of hands for play due to } \\
\text { thumb stuck in palm }\end{array}$ & $\begin{array}{l}\text { Slight attempt to go back to } \\
\text { extension }\end{array}$ & $\begin{array}{l}\text { No binocular sustained fixation on } \\
\text { target }\end{array}$ \\
\hline 0 & $\begin{array}{l}\text { Use fingers to explore sensory-based } \\
\text { toys }\end{array}$ & Maintain for I sec & $2 \mathrm{sec}$ fixation \\
\hline+1 & $\begin{array}{l}\text { Maintain grasp on cylinder object for } 5 \\
\text { sec }\end{array}$ & $30 \mathrm{sec}$ & Fixate on two with sifts \\
\hline+2 & $\begin{array}{l}\text { Maintain grasp on cylinder object for } 10 \\
\text { sec }\end{array}$ & I minute standing & $\begin{array}{l}\text { Focus on } 3 \text { objects in different focal } \\
\text { lengths ( } 20 \% \text { aquity) }\end{array}$ \\
\hline
\end{tabular}

Table VIII (I): Calculated sum of GAS for participant one

\begin{tabular}{|l|c|c|c|c|c|}
\hline Goal (RJ) & Importance & Difficulty & Weight (I X D) & Baseline Score & Outcome Score \\
\hline Sustained cylindrical grasp on spoon during feeding & 3 & 3 & 9 & -2 & +2 \\
\hline Spontaneous kicking for self-regulation & 3 & 3 & 9 & -2 & +2 \\
\hline Mouth closure on spoon during feeding & 3 & 2 & 6 & -2 & +2 \\
\hline \multicolumn{7}{|c|}{ Sum = 24 } \\
\hline
\end{tabular}

Table VIII (2): Calculated sum of GAS for participant two

\begin{tabular}{|l|c|c|c|c|c|}
\hline Goal (RC) & Importance & Difficulty & Weight (I X D) & Baseline Score & Outcome Score \\
\hline Maintain object in hand & 3 & 3 & 9 & -2 & +2 \\
\hline Starting in frame for conversations & 3 & 3 & 9 & -2 & +2 \\
\hline Encourage arm use by transfer over hemi arm & 3 & 3 & 6 & -2 & +2 \\
\hline \multicolumn{7}{|c|}{ Sum = 29 } \\
\hline
\end{tabular}

Table VIII (3): Calculated sum of GAS for participant three

\begin{tabular}{|l|c|c|c|c|c|}
\hline Goal (MvW) & Importance & Difficulty & Weight (I X D) & Baseline Score & Outcome Score \\
\hline Hold cylinder object with movement & 3 & 3 & 9 & -2 & +2 \\
\hline Standing in frame for conversations & 3 & 3 & 9 & -2 & +2 \\
\hline Voicing to get mom's attention & 3 & 3 & 6 & -2 & +2 \\
\hline \multicolumn{7}{|c|}{ Sum = 27 } \\
\hline
\end{tabular}


Table VIII (4): Calculated sum of GAS for participant four

\begin{tabular}{|l|c|c|c|c|c|}
\hline Goal (RK) & Importance & Difficulty & Weight (I X D) & Baseline Score & Outcome Score \\
\hline Grasp for manipulation & 3 & 3 & 9 & -2 & +2 \\
\hline $\begin{array}{l}\text { Standing with assistance for transfer from } \\
\text { wheelchair to bed }\end{array}$ & 3 & 3 & 9 & -2 & +2 \\
\hline Focusing for alternative communication & 3 & 3 & 9 & -2 & +2 \\
\hline \multicolumn{7}{|l|}{ Sum = 29 } \\
\hline
\end{tabular}

CP: Constraint-Induced, Movement Therapy, Bimanual Training, context-focused therapy, goal-directed/functional training, Occupational Therapy following BoNT-A and home programmes for improving motor activity performance and/or self-care. Our study endorsed the review findings of Novak et a ${ }^{15}$ ie constraint-induced therapy, context-focused therapy, goal-directed/functional training and home programmes.

Completing the PEDI-CAT increased the awareness of mothers of children with $\mathrm{CP}$ about their child's progress in relation to typical skill-acquisition patterns and level of assistance provided in daily activities. Using task specificity training ${ }^{17,18}$ with the involvement of the parents, should be the way forward with intervention of the child with $\mathrm{CP}$.

Using GAS goals were an appropriate choice for this pilot study. In this study the T-scores are $>50^{34}$ and showed an improvement in the participants' development (Table VIII (I-4) page 3I and 32).

\section{LIMITATIONS OF THE STUDY}

Although this was a pilot study, the small sample size was a limitation.

A further limitation was in the use of the One-Group Pre-testPost-test Design design ${ }^{23}$. The maturation with change within the participants could have an effect on the measurements ${ }^{33}$.

The Paediatric Rehabilitation Observational measure of Fidelity $(P R O F)^{35}$ was not used for this pilot study. Even though with no training in the PROF, an observation could be made that the CTP would score well, as the intervention sessions complied with all but five of the 37 non-specific items on the $\mathrm{PROF}^{36}$.

Only an occupational therapist as interventionist may be a limitation. An interdisciplinary intervention team including a physiotherapist and speech therapist would have been preferable.

\section{RECOMMENDATIONS AND CONCLUSION}

This pilot study showed that the Bobath/NDT approach is not the only approach for intervention of children with CP. It is recommended that the NDT/Bobath approach should be implemented in intervention sessions incorporating several systems that influence specific tasks, together with targeted functional training. Furthermore, it is recommended to make use of a holistic intervention method of other complimentary treatment modalities and approaches pending on the needs and goals of the child and family. Even though the body of knowledge gained by Bobath/NDT training caters for a holistic approach when intervention is done for the child with $\mathrm{CP}$, there is little or no scientific proof of the effect of the approach. Although there is consistent evidence that NDT/Bobath produced an immediate improvement in dynamic range of motion it does not render sufficient evidence of a long term effect ${ }^{32}$.

This study brought to question the level of education and clinical experience of a NDT/Bobath tutor, as well as by whom they were educated. The performance of the patient related to the performance of a tutor or therapist, but to measure this performance needs to be studied. The partnership between the family and the intervention team (occupational therapist) produced better results than excluding them in setting goals ${ }^{13}$.

We hypothesised that children with $\mathrm{CP}$ who follow an optimal dosage $^{21}$ of a holistic intervention will lead to functional improvement in totality. Dosage, in this article includes frequency, intensity, time and type of activity. The findings did indicate that 25 hours for five consecutive days and the task specificity ${ }^{17}$ as an active chal- lenging practice had a positive functional effect that lasted for eight weeks. This high dosage may be maintainable.

This study resulted in the CTP development and the principles may be used in future studies as an intervention protocol for children with CP. A follow-up study is needed with a larger sample size using PROF ${ }^{35}$.

In conclusion, no significant increases were measured, but a clinical significance was indicated through the results of the GAS scores. The results therefore suggest that a larger, multicultural study should be done to find definitive answers regarding the benefits of the NDT/Bobath approach. This study acts as a stepping stone towards more standardised intervention protocols, specifically for the child with $\mathrm{CP}$.

\section{IMPLICATION FOR OCCUPATIONAL THERAPY}

As occupational therapists, we are in a unique position with our holistic client-centred approach to manage children with $\mathrm{CP}$ successfully. More emphasis should be on dosage of intervention sessions, which includes frequency, intensity, time, type of activity and task specificity.

\section{ACKNOWLEDGEMENTS}

We would like to acknowledge $\operatorname{Dr} S$ Capelovitch for support and advice in preparing the protocol. Mr C van Rooyen the Biostatistician for advice and support on the results. We are grateful to the videographers during this pilot study, Manus Conradie, Faye Campbell, Bronwyn Kemp and Priscilla Taljaard. We acknowledge Johané Nienkemper-Swanepoel for the statistical support of the GAS and the editing of this manuscript.

\section{REFERENCES}

I. Fetters $L$ \& Kluzik JA. The effects of neurodevelopmental treatment versus practice on the reaching of children with spastic cerebral palsy. Physical Therapy. 1996; 76(4): 346-58.

2. Arndt SW, Chandler LS, Sweeney JK, Sharkey MA \& McElroy JJ. Effects of a Neurodevelopmental Treatment-Based Trunk Protocol for Infants with Posture and Movement Dysfunction. Pediatric Physical Therapy. 2008; 20: II-22.

3. Paci M. Physiotherapy based on the Bobath concept for adults with post-stroke hemiplegia: A Review of effectiveness studies. Journal Rehabilitation Medicine. 2003; 35: 2-7.

4. Novak I, Mcintyre S, Morgan C, Campbell L, Dark L, Morton N, Stumbles E, Wilson SA \& Goldsmith S. A systematic review of interventions for children with cerebral palsy: state of the evidence. Developmental Medicine \& Child Neurology. 20I3; 55: 885-9I0.

5. Capelovitch S. Neurodevelopmental therapy - a popular approach Developmental Medicine \& Child Neurology. 20I4; 56: 390-406.

6. Papavasiliou AS. Management of motor problems in cerebral palsy: A critical update for the clinician. European Journal of Paediatric Neurology. 2009; 13: 387-396.

7. Kleim JA, Barbay S \& Nudo RJ. Functional Reorganization of the Rat Motor Cortex Following Motor Skill Learning. Journal of Neurophysiology. 1998; 80: 332I-3325. Available at (http://in.physiology. org/content/jn/80/6/332I full.pdf) Retrieved on 4 November 2014.

8. World Health Organization. International Classification of Functioning, Disability and Health (ICF-CY). Geneva: World Health Organisation; 2006.

9. Mayston MJ. The Bobath Concept Today. Synapse (Journal and 
Newsletter of the Association of Chartered Physiotherapists interested in Neurology. ACPIN) 2000; Spring: 32-35. Available at (http://www.bobath.org.uk/wp-content/uploads/2013/09/Synapsethe-bobath-concept-today.pdf) Retrieved on 2 May 2014.

10. Rosenbaum $P$ Paneth $N \&$ Leviton A. A report: the definition and classification of cerebral palsy. Developmental Medicine and Child Neurology. 2007; 49 (suppl. 109): 8-II.

II. Hadders-Algra, M. The neuronal group selection theory: promising principles for understanding and treating developmental motor disorders. Developmental Medicine \& Child Neurology. 2000; 42: 707-7I5.

12. Shumway-Cook A \& Woollacott MH. Motor Control: Translating Research into Clinical Practice. $4^{\text {th }}$ ed. Philadelphia: Lippincott Williams \& Wilkens; 2012.

13. Muratori LM, Lamberg EM, Quinn L \& Duff SV. Applying principles of motor learning and control to upper extremity rehabilitation. Journal of Hand Therapy. 2013; 26(2): 94-103.

14. Boyt-Schell BA, Scaffa ME, Gillen G \& Cohn ES. Contemporary Occupational Therapy Practice. Willard HS \& Boyt-Schell BA (eds). Willard and Spackman's Occupational Therapy. $12^{\text {th }}$ ed. Philadelphia: Wolters Kluwer/Lippincot Williams \& Wilkins; 20I4: 47-58.

15. Witt JK. Action's Effect on Perception. Current Directions in Psychological Science. 20I I; 20(3): 20I-206.

16. Watling R. Interventions and strategies for challenging behaviors. Case-Smith J \& O'Brien C (eds). Occupational Therapy for Children. $6^{\text {th }}$ ed. Mosby, Philadelphia: Elsevier Inc.; 20 I0: 434-445.

17. Gordon AM, Hung YC, Brandao M, Ferre CL, Kuo HC, Friel K, Petra E, Chinnan A \& Charles JR. Bimanual Training and ConstraintInduced Movement Therapy in Children With Hemiplegic Cerebral Palsy: A Randomized Trial. Neurorehabilitation and Neural Repair. 20I I; 25(8): 692-702.

18. Novak I, Morgan C, Adde L, Blackman J, Boyd RN, BrunstromHernandez J, Cioni G, Damiano D, Darrah J, Eliasson A, de Vries, LS, Einspieler C, Fahey M, Fehlings D, Ferriero DM, Fetters L, Fiori S, Forssberg H, Gordon AM, Greaves S, Guzzetta A, Hadders-Algra M, Harbourne R, Kakooza-Mwesige A, Karlsson P, Krumlinde-Sundholm L, Latal B, Loughran-Fowlds A, Maitre N, Mclntyre S \& Noritz G. Early, Accurate Diagnosis and Early Intervention in Cerebral Palsy. Advances in Diagnosis and Treatment. JAMA Pediatrics. 2017; I7I(9): 897-907

19. Nordstrand L, Holmefur M, Kits A \& Eliasson A. Improvements in bimanual hand function after baby-CIMT in two-year old children with unilateral cerebral palsy: A retrospective study. Research in Developmental Disabilities. 20I5, 4I-42: 86-93.

20. Wittenberg GF. Neural plasticity and treatment across the lifespan for motor deficits in cerebral palsy. Developmental Medicine \& Child Neurology, 2009; 5 I (suppl.4):I30-I33.

21. Gannotti ME, Christy JB, Heathcock JC, Thubi HA \& Kolobe. A Path Model for Evaluating Dosing Parameters for Children With Cerebral Palsy. Physical Therapy. 2014; 94(3): 4II-42I.

22. Russell D, van Heerden R, van Vuuren S, Venter A, Joubert G. Time management guidelines for intervention of a child with Down syndrome using the Developmental Resource Stimulation Programme (DRSP). South Africa Journal of Occupational Therapy. 2016; 46(I): 42-45.

23. Taylor RR, Fossey E \& Kielhofner G. Selecting the Research Method. Taylor RR. Kielhofner's Research in Occupational Therapy: Methods of Inquiry for Enhancing Practice. $2^{\text {nd }}$ ed. Philadelphia: FA Davis Company; 2017: 119-134.

24. Strydom H. Sampling and sampling methods. In De Vos AS, Strydom $\mathrm{H}$, Fouché CB \& Delport CSL (eds). Research at Grass Roots For the Social Sciences and Human Service Profession. $3^{\text {rd }}$ ed. Pretoria: Van Schaik; 201 I: 222-235.

25. Russell DJ, Rosenbaum PL, Avery LM \& Lane M. Gross Motor Function Measure (GMFM-66\&GMFM-88) User's Manual. London: Mac Keith Press; 2002: I, 4I, 42, 153.

26. Scholtz CE. Eye movements and postural alignment in children with Cerebral Palsy. Master's Thesis. UFS. 2013.

27. Haley SM, Coster WJ, Ludlow LH, Haltiwanger JT \& Andrellos PJ. Pediatric Evaluation of Disability Inventory: Development, Standardization and Administration Manual. PsychCorp; Pearson, United States. 1994. Available at (http://www.pearsonclinical.com/therapy/ products/100000505/pediatric-evaluation-of-disability-inventroy- pedi.html) Retrieved 5 May 2014.

28. Bowman J. Gross Motor Function Measure (GMFM) General Information Summary: Developed by D. Russell, P. Rosenbaum, C. Gowland, S. Hardy, M. Lane, N. Plews, H. McGavin, D. Cadman \& S. Jarvis; 2005.

29. Krasny-Pacini A, Hiebel J, Pauly F, Godon S \& Chevignard M. Goal Attainment Scaling in rehabilitation: A literature-based update. Annals 2 I 4 of Physical and Rehabilitation Medicine. 20I3; 56: 2I 2-230. Available at (http://www.sciencedirect.com) Retrieved 5 May 2014.

30. Bovend'Eerdt TJH, Botell RE \& Wade DT. 2009. Writing SMART rehabilitation goals and achieving goal attainment scaling: a practical guide. Clinical Rehabilitation. 2009; 23: 352-36I.

31. Kleim JA\& Jones TA. Principles of experience-dependent neural plasticity: implications for rehabilitation after brain damage. Journal of Speech, Language and Hearing Research. Feb. 2008; 5 I (I): S225-39.

32. Butler C \& Darrah J. AACPDM Evidence Report: Effects of Neurodevelopmental Treatment (NDT) for Cerebral Palsy. Developmental Medicine and Child Neurology. 200I; 43: 778-790.

33. Leedy PD \& Ormrod JE. Practical Research Planning and Design. $9^{\text {th }}$ ed. New Jersey, US: Pearson Education, Inc.; 2010.

34. Turner-Stokes L. Goal attainment scaling (GAS) in rehabilitation: a practical guide. Clinical Rehabilitation. 2009; 23: 262-370.

35. Di Rezze BM. Measurement of intervention fidelity within paediatric rehabilitation for children with physical disabilities. PhD Thesis, McMaster University; 2012.

36. Di Rezze BM, Law M, Eva K, Pollock N \& Gorter JW. Development of a generic fidelity measure for rehabilitation intervention research for children with physical disabilities. Developmental Medicine \& Child Neurology. 20 I 3; 55: 737-744.

\section{Corresponding Author}

\section{Dorothy Russell}

russeldc@ufs.ac.za 